Article

\title{
Peer Support Needs and Preferences for Digital Peer Navigation among Adolescent and Young Adults with Cancer: A Canadian Cross-Sectional Survey
}

\author{
Jacqueline L. Bender ${ }^{1,2,3,4, *}$, Natasha Puri ${ }^{1}$, Sarah Salih ${ }^{1}$, Norma M. D'Agostino ${ }^{2}$, Argerie Tsimicalis ${ }^{5}$

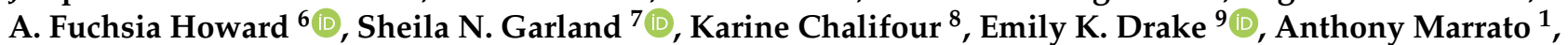 \\ Nikki L. McKean ${ }^{1}$ and Abha A. Gupta ${ }^{2,10}$
}

check for

updates

Citation: Bender, J.L.; Puri, N.; Salih, S.; D’Agostino, N.M.; Tsimicalis, A.

Howard, A.F.; Garland, S.N.

Chalifour, K.; Drake, E.K.; Marrato,

A.; et al. Peer Support Needs and

Preferences for Digital Peer

Navigation among Adolescent and

Young Adults with Cancer: A

Canadian Cross-Sectional Survey.

Curr. Oncol. 2022, 29, 1163-1175.

https://doi.org/10.3390/

curroncol29020099

Received: 10 January 2022

Accepted: 7 February 2022

Published: 16 February 2022

Publisher's Note: MDPI stays neutral with regard to jurisdictional claims in published maps and institutional affiliations.

Copyright: (C) 2022 by the authors Licensee MDPI, Basel, Switzerland. This article is an open access article distributed under the terms and conditions of the Creative Commons Attribution (CC BY) license (https:// creativecommons.org/licenses/by/ $4.0 /)$.
1 Cancer Rehabilitation and Survivorship, Princess Margaret Cancer Centre, University Health Network, Toronto, ON M5G 2C4, Canada; npuri@sgu.edu (N.P.); sarah.salih@uhnresearch.ca (S.S.); anthony@marrato.com (A.M.); nikki@nikkileighmckean.com (N.L.M.)

2 Department of Supportive Care, Princess Margaret Cancer Centre, University Health Network, Toronto, ON M5G 2C1, Canada; norma.dagostino@uhn.ca (N.M.D.); abha.gupta@uhn.ca (A.A.G.)

3 Dalla Lana School of Public Health, University of Toronto, Toronto, ON M5T 3M7, Canada

4 Institute of Health Policy, Management and Evaluation, University of Toronto, Toronto, ON M5T 3M7, Canada 5 Ingram School of Nursing, McGill University, Montreal, QC H3A 2M7, Canada; argerie.tsimicalis@mcgill.ca

6 School of Nursing, The University of British Columbia, Vancouver, BC V6T 2B5, Canada; Fuchsia.Howard@ubc.ca

7 Department of Psychology, Memorial University, St. John's, NL A1C 3X9, Canada; sheila.garland@mun.ca

8 Young Adult Cancer Canada, St. John's, NL A1B 3K3, Canada; karine@youngadultcancer.ca

9 Faculty of Health, Dalhousie University, Halifax, NS B3H 4R2, Canada; emily.drake@dal.ca

10 Adolescent and Young Adult Cancer Program, Princess Margaret Cancer Centre, University Health Network, Toronto, ON M5G 2C1, Canada

* Correspondence: jackie.bender@uhnresearch.ca; Tel.: +1-416-581-8606

\begin{abstract}
Adolescents and young adults (AYA) with cancer desire peer support and require support programs that address their unique needs. This study investigated the need for, and barriers to, peer support and preferences for digital peer navigation among AYA. A cross-sectional survey was administered to AYA, diagnosed with cancer between the ages of 15-39, at a cancer center and through social media. Descriptive summary statistics were calculated. Participants $(n=436)$ were on average 31.2 years $(\mathrm{SD}=6.3), 3.3$ years since-diagnosis $(\mathrm{SD}=3.8)$, and $65 \%(n=218)$ were women. Over three-quaters $(n=291,76.6 \%)$ desired peer support from cancer peers, but $41.4 \%(n=157)$ had not accessed peer support. Main access barriers were: Inconvenience of in-person support groups ( $n=284,76.1 \%$ ), finding AYA with whom they could relate $(n=268,72.4 \%)$, and finding AYA-specific support programs $(n=261,70.4 \%)$. Eighty-two percent $(n=310)$ desired support from a peer navigator through a digital app, and $63 \%(n=231)$ were interested in being a peer navigator. Participants indicated a greater need for emotional $(n=329,90.1 \%)$ and informational support $(n=326,89.1 \%)$ than companionship $(n=284,78.0 \%)$ or practical support $(n=269,73.6 \%)$ from a peer navigator. Foremost peer matching characteristics were cancer-type $(n=329,88.4 \%)$, specific concerns $(n=317,86.1 \%)$, and age-at-diagnosis $(n=316,86.1 \%)$. A digital peer navigation program was desired by over $80 \%$ of a large Canadian sample of AYA and could potentially overcome the barriers AYA experience in accessing peer support. The design of a peer navigation program for AYA should consider the matching characteristics and multidimensional support needs of AYA.
\end{abstract}

Keywords: adolescents and young adults; cancer; peer support; navigation; digital health

\section{Introduction}

Adolescents and young adults (AYA; defined as individuals diagnosed with cancer between the ages of 15 and 39) comprise a distinct cancer population with unique needs [1]. 
Due to their age and life stage at diagnosis, AYA are confronted with a multitude of physical, psychosocial, and socioeconomic impacts of cancer that are disproportionately greater than in older adults [1]. AYA report higher levels of distress, more severe side effects, interrupted education, careers, and relationships, disconnection from peers, and financial hardship [2-6]. Many AYA lack the life experience and skills to cope with these significant challenges [7], yet healthcare systems provide inadequate or inaccessible support [8-10], resulting in a high burden of unmet needs [9-12].

To overcome these significant challenges, support programs that connect AYA with same-age cancer peers, as well as provide practical knowledge and skills to navigate the healthcare system are needed [13-15]. In a Canadian hospital-based survey, 56\% of 127 AYA that were surveyed indicated a desire for peer support from other AYA [16]. In a Canadian qualitative study, AYA recommended a buddy system linking patients to peer mentors to navigate the healthcare system [14]. Support from a cancer peer provides unique reassurance and practical information that can reduce distress and enhance coping [17-20]. However, AYA report limited opportunities to interact with other AYA and encounter significant challenges in forming new social relationships [11].

Patient navigation is a well-documented approach that can overcome gaps in access to care and support [21-26]. Peer navigation, a type of patient navigation, enlists trained cancer survivors as navigators [27]. Digital technologies could enhance access to peer navigation and are preferred by AYA [28]. However, few studies have investigated navigation among AYA, and even less have explored the use of digital technologies to facilitate navigation [22]. One qualitative study of the navigation preferences of American AYA, found that all developmental age groups (e.g., 15-18, 19-25, 26-39) were interested in navigation, with most preferring an initial face-to-face interaction followed by a technology-mediated interactions (e.g., by telephone, text or email) [15]. One randomized controlled trial compared an automated text-messaging support intervention versus telephone-based peer navigation (from same-aged non-cancer peers) to usual care among a sample of American AYA [29]. The text messaging group had higher survivorship care knowledge, while the peer navigation group had higher survivorship care self-efficacy compared to usual care [29].

Research is needed to better understand the peer support needs of Canadian AYA and their interest in peer navigation. While the US data are helpful, they cannot be directly extrapolated to the Canadian context, given the different healthcare and social systems. Therefore, this study examined the need for, and barriers to, peer support and preferences for digital peer navigation among a sample of AYA in Canada. Guided by the Canadian Strategy for Patient-Oriented Research (SPOR) [30], AYA were engaged as patient partners and collaborators on the study team. There are many benefits to engaging patients in health research, not limited to improvements in research relevance, patient enrollment and retention, as well as the translation of study findings into clinical practice [31,32]. Moreover, for the present study, engaging with patient partners from the onset was critical to inform the design of a future solution tailored to the self-reported peer support needs and preferences of AYA.

\section{Materials and Methods}

\subsection{Study Design}

A cross-sectional survey design was employed, following the Strengthening the Reporting of Observational Studies in Epidemiology (STROBE) guidelines [33]. Ethics approval was obtained by the University Health Network (UHN) Research Ethics Board.

\subsection{Setting}

The survey was distributed to AYA at the Princess Margaret Cancer Center (PM) in Toronto, Ontario, Canada, and online from September 2018 to April 2019. The PM has an AYA Program that provides specialized support to younger people (less than 40 years old) living with cancer. Patients who participate in the PM AYA Program meet one-on-one 
with an AYA Clinical Nurse Specialist to identify where additional support is needed. Patients can sign up to receive a monthly e-newsletter that provides program updates and information on upcoming AYA-specific events. The PM AYA Program also supports an 8-week Mindfulness-Based Cognitive Therapy course, a 6-week music therapy group, and monthly virtual peer support drop-in meetings for AYA. All of the resources and events are promoted online through the AYA PM social media (SM) channels.

At PM, AYA were recruited using a weekly report that identifies all patients who are less than 40 years of age attending disease site ambulatory clinics, including those diagnosed with: leukemia, lymphoma, breast cancer, genitourinary cancer, central nervous system cancer, head/neck cancer, sarcoma, gastrointestinal cancer, and gynecological cancer. Patients were approached during routine appointments, informed about the survey, and if agreeable, consented to study participation, and were given a paper copy of the survey.

To recruit AYA outside of PM, the study team distributed the survey via SM using a targeted digital recruitment strategy, that followed Bender's privacy-by-design framework for online recruitment [34]. A recruitment notice was posted on team members' SM channels and on the PM AYA program's Twitter account, Instagram channel, and Facebook page, with a link to the online survey. The SM recruitment notice contained a concise study description, an image of young adults, a disclaimer regarding the privacy limitations of SM, and the contact information for the study team. The SM recruitment post with the survey link was shared along with relevant hashtags, including \#AYACSM (Adolescent and Young Adult Cancer Societal Movement). The study information was also shared by email to members of the PM AYA Program e-newsletter listserv, community partners, and individual contacts. Specific community partners who shared the SM recruitment notice included Young Adult Cancer Canada (YACC) and members of the \#AYACSM community.

To encourage survey completion, participants were offered the opportunity to be entered into a draw to win one of three CAD \$100 Amazon gift cards upon completion of the survey.

\subsection{Participants}

Individuals were eligible to participate if they were diagnosed with cancer between the ages of 15 to 39 years, able to read and speak English, and were receiving treatment for cancer or within 10 years of treatment completion.

\subsection{Questionnaire}

The survey contained four sections and 57 questions comprising standardized and author-developed measures. It was pilot tested with four AYA before administration. The four survey sections were, "A. Cancer Specific Background Information”, "B. Preferences for Peer Support from other Adolescents and Young Adults (AYA) Diagnosed with Cancer", "C. Overall Health and Wellbeing", and "D. Background Information About You". This manuscript reports on responses to questions in sections $\mathrm{A}, \mathrm{B}$ and $\mathrm{D}$, including participant demographics and disease characteristics, the need for and barriers to peer support, and interest and preferences for digital peer navigation (Supplementary Materials).

\subsection{Statistical Methods}

Descriptive analyses were conducted using SPSS version 25. Means and standard deviations were calculated for continuous variables and proportions for categorical variables. Response options for several demographic characteristics, as well as for items querying satisfaction with peer support received from other AYA and importance of training for the peer navigator role were collapsed and are described in the subsequent tables. For barriers to peer support, response options were dichotomized into no problem versus a problem (somewhat of a problem, big problem, not sure). For matching characteristics, response options were dichotomized into not at all important versus important (not sure, somewhat important, important). For the type of support desired from a peer navigator, response 
options were dichotomized into not at all important versus important (slightly, moderately, important, very important).

\section{Results}

\subsection{Participant Characteristics}

In total, 436 participants completed the survey, of which 217 (49.8\%) participants were recruited from PM and 219 (50.2\%) through SM. Participants were on average 31 years of age and 3.3 years post diagnosis (Table 1). Most were diagnosed with breast cancer $(n=91,21.7 \%)$ and Hodgkin's Lymphoma $(n=47,11.2 \%)$, with fairly equal numbers of participants diagnosed with testicular cancer, leukemia, sarcoma, and thyroid cancer (8-9\% each). About two-thirds of the participants identified as women $(n=218,65.1 \%)$, heterosexual ( $n=286,64.6 \%)$, and white $(n=212,63.1 \%)$, and had completed at least some university $(n=216,63.1 \%)$. Most of the participants lived in urban or suburban settings $(n=292,86.9 \%)$ in the province of Ontario $(n=274,81.3 \%)$.

Table 1. Participant characteristics.

\begin{tabular}{|c|c|c|}
\hline Characteristic & Category & $\begin{array}{l}\text { Count (\%), Unless } \\
\text { Otherwise Specified }\end{array}$ \\
\hline Age (years), mean (SD), $(n=419)$ & & $31.3(6.3)$ \\
\hline Age at Diagnosis (years), mean (SD), $(n=412)$ & & $28.0(6.8)$ \\
\hline Time Since Diagnosis (years), mean (SD), $(n=415)$ & & $3.3(3.8)$ \\
\hline \multirow[t]{10}{*}{ Cancer Type $(n=419)$} & Breast & $91(21.7)$ \\
\hline & Hodgkin's Lymphoma & $47(11.2)$ \\
\hline & Testicular & $41(9.8)$ \\
\hline & Leukemia & $36(8.6)$ \\
\hline & Sarcoma & $35(8.4)$ \\
\hline & Thyroid & $32(7.6)$ \\
\hline & Gastrointestinal, colorectal, liver & $31(7.4)$ \\
\hline & Gynecological (Cervical, ovarian, uterine) & $27(6.4)$ \\
\hline & Non-Hodgkin's Lymphoma & $25(6.0)$ \\
\hline & Other & $54(12.9)$ \\
\hline \multirow[t]{6}{*}{ Treatment Types $(n=419)$} & Chemotherapy & $311(74.2)$ \\
\hline & Hormone & $70(16.7)$ \\
\hline & Radiation & $175(41.8)$ \\
\hline & Surgery & $254(60.6)$ \\
\hline & Bone Marrow Transplant & $22(5.3)$ \\
\hline & Other & $51(12.2)$ \\
\hline \multirow[t]{4}{*}{ Gender $(n=337)$} & Woman & $218(65.1)$ \\
\hline & Man & $117(34.7)$ \\
\hline & Transgender & $0(0)$ \\
\hline & Prefer not to answer & $2(0.6)$ \\
\hline \multirow[t]{3}{*}{ Sexual Orientation $(n=335)$} & Heterosexual & $286(85.4)$ \\
\hline & Homosexual/Bisexual/Other & $41(12.3)$ \\
\hline & Prefer not to answer & $8(2.4)$ \\
\hline \multirow[t]{2}{*}{ Country of Birth $(n=337)$} & Canada & $251(74.5)$ \\
\hline & Other & $86(25.5)$ \\
\hline
\end{tabular}


Table 1. Cont.

\begin{tabular}{|c|c|c|}
\hline Characteristic & Category & $\begin{array}{l}\text { Count }(\%), \text { Unless } \\
\text { Otherwise Specified }\end{array}$ \\
\hline \multirow[t]{3}{*}{ Race/Ethnicity $(n=336)$} & White & $212(63.1)$ \\
\hline & Not White/Not Indigenous & $111(34.5)$ \\
\hline & Indigenous & $13(3.9)$ \\
\hline \multirow[t]{10}{*}{ Province where you currently live $(n=337)$} & Newfoundland & $6(1.8)$ \\
\hline & Nova Scotia & $6(1.8)$ \\
\hline & Quebec & $11(3.3)$ \\
\hline & Ontario & $274(81.3)$ \\
\hline & Manitoba & $11(4.2)$ \\
\hline & Saskatchewan & $1(0.3)$ \\
\hline & Alberta & $13(2.7)$ \\
\hline & British Columbia & $9(2.7)$ \\
\hline & Northwest Territories & $1(0.3)$ \\
\hline & I do not currently live in Canada & $2(0.6)$ \\
\hline \multirow[t]{2}{*}{ Size of setting where you currently live $(n=336)$} & Urban or suburban (e.g., city) & $292(86.9)$ \\
\hline & Town or rural (e.g., country) & $44(13.1)$ \\
\hline \multirow[t]{2}{*}{ Current school or employment status $(n=338)$} & Employed and/or Student & $272(80.5)$ \\
\hline & Unemployed & $66(19.5)$ \\
\hline \multirow[t]{3}{*}{ Highest level of education $(n=340)$} & Completed/Some University * & $216(63.5)$ \\
\hline & Completed/Some College* & $84(23.7)$ \\
\hline & High school or less & $28(8.9)$ \\
\hline \multirow[t]{4}{*}{ Personal income $(n=336)$} & Less than CAD 40,000 or no income/ not working & $161(47.9)$ \\
\hline & CAD 40,000 to less than CAD 80,000 & $87(25.9)$ \\
\hline & CAD 80,000 or more & $49(14.6)$ \\
\hline & Prefer not to answer & $38(11.3)$ \\
\hline
\end{tabular}

* In Canada, colleges offer Diploma and Certificate programs, while universities offer Bachelor, Master's, and Doctoral degrees.

\subsection{Need for and Use of Peer Support}

Over three-quarters of the participants $(n=291,76.6 \%)$ desired peer support from other AYA since their diagnosis (Table 2$)$. However, $41.4 \%(n=157)$ had not accessed peer support. Two-thirds $(n=237,62 \%)$ reported that they had discussed peer support with a medical professional. Of these, $50 \%(n=191)$ indicated that their medical professional initiated the conversation, while $12 \%(n=46)$ indicated that they had initiated the conversation regarding peer support. Slightly more than a third ( $n=143,37.3 \%)$ received a referral to a peer support program. The most common method of connecting with other AYA was through SM ( $n=152,40.1 \%)$.

Participants indicated a greater need for emotional ( $n=168,45.2 \%)$, informational ( $n=159,42.7 \%$ ), and companionship support (e.g., hang out and perform social things) $(n=161,43.6 \%)$ from other AYA, than practical support $(n=105,28.5 \%)$. Of the participants who received peer support from other AYA $(n=198,52.2 \%), 70 \%(n=139)$ were satisfied with the support they received. 
Table 2. Needs and preferences for peer support.

\begin{tabular}{|c|c|c|}
\hline Characteristic $(n)$ & Category & Count $(\%)$ \\
\hline Desire to connect with other AYA $(n=380)$ & Yes & $291(76.6)$ \\
\hline \multirow[t]{3}{*}{$\begin{array}{l}\text { Talked to a medical professional regarding peer support } \\
(n=382)\end{array}$} & Yes, a medical professional initiated the conversion & $191(50.0)$ \\
\hline & Yes, I initiated the conversation & $46(12.0)$ \\
\hline & No & $145(38.0)$ \\
\hline Received a referral to a peer support program $(n=383)$ & Yes & $143(37.3)$ \\
\hline \multirow[t]{9}{*}{ Methods used to connect with other AYA $(n=379)$} & Social media & $152(40.1)$ \\
\hline & Cancer organizations & $117(30.9)$ \\
\hline & In-person support groups & $85(22.4)$ \\
\hline & Camps, retreats, and adventure groups & $67(17.7)$ \\
\hline & Online discussion forums & $51(13.5)$ \\
\hline & Healthcare professional & $50(13.2)$ \\
\hline & Conference & $50(13.2)$ \\
\hline & Telephone support service & $21(5.5)$ \\
\hline & Digital apps & $12(3.2)$ \\
\hline \multicolumn{3}{|l|}{ Can you count on another AYA to (fill in with your answer) } \\
\hline \multirow[t]{3}{*}{$\begin{array}{l}\text { Provide you with good information or advice regarding a } \\
\text { problem? }(n=372)\end{array}$} & $\begin{array}{l}\text { I would like/or I would like more of this type of } \\
\text { peer support }\end{array}$ & $159(42.7)$ \\
\hline & I have this type of support & $95(25.5)$ \\
\hline & Not needed & $118(31.7)$ \\
\hline \multirow[t]{3}{*}{ Provide you with emotional support? $(n=372)$} & $\begin{array}{l}\text { I would like/or I would like more of this type of } \\
\text { peer support }\end{array}$ & $168(45.2)$ \\
\hline & I have this type of support & $85(22.8)$ \\
\hline & Not needed & $119(32.0)$ \\
\hline \multirow[t]{3}{*}{$\begin{array}{l}\text { Provide you with practical help with things, such as daily } \\
\text { chores, child care or getting to appointments? }(n=368)\end{array}$} & $\begin{array}{l}\text { I would like/or I would like more of this type of } \\
\text { peer support }\end{array}$ & $105(28.5)$ \\
\hline & I have this type of peer support & $22(6.0)$ \\
\hline & Not needed & $241(65.5)$ \\
\hline \multirow[t]{3}{*}{ Hang out with and perform normal social things? $(n=370)$} & $\begin{array}{l}\text { I would like/or I would like more of this type of } \\
\text { peer support }\end{array}$ & $161(43.6)$ \\
\hline & I have this type of peer support & $71(19.2)$ \\
\hline & Not needed & $138(37.3)$ \\
\hline \multirow[t]{4}{*}{$\begin{array}{l}\text { Satisfaction with peer support received from other AYA } \\
(n=379)\end{array}$} & Very Satisfied/Satisfied & $139(36.7)$ \\
\hline & Neutral & $49(12.9)$ \\
\hline & Very Dissatisfied/Dissatisfied & $10(2.6)$ \\
\hline & N/A, I have not received support from other AYA & $181(47.8)$ \\
\hline
\end{tabular}

\subsection{Barriers to Accessing Peer Support}

The top three barriers to accessing peer support from other AYA, reported by more than $70 \%$ of the sample, were the inconvenience of in-person support groups $(n=285$, $76.1 \%)$, finding AYA with whom they can relate to $(n=268,72.4 \%)$, and finding AYAspecific support programs $(n=261, n=70.4 \%$ ) (Table 3$)$. The least commonly endorsed access barriers were related to technical challenges. Less than $8 \%$ found SM difficult to use, 
less than $7 \%$ had difficulty accessing a computer or mobile device, and less than $4 \%$ had difficulty using a computer or a mobile device.

Table 3. Barriers to accessing peer support.

\begin{tabular}{lll}
\hline Frequency & Variable $(n)$ & Count (\%) \\
\hline 1 & In-person support programs were not convenient to attend $(n=373)$ & $284(76.1)$ \\
\hline 2 & Finding another AYA who I can relate to was difficult for me $(n=370)$ & $268(72.4)$ \\
\hline 3 & AYA specific in-person support programs were hard to find $(n=371)$ & $261(70.4)$ \\
\hline 4 & Unsure of where or how to find other AYA $(n=373)$ & $257(68.9)$ \\
\hline 6 & Uncomfortable attending in-person support programs $(n=373)$ & $247(66.12)$ \\
\hline 7 & Concerned about presence around negative minded cancer patients $(n=372)$ & $223(59.9)$ \\
\hline 8 & Concerned about getting close to someone who might die $(n=370)$ & $208(56.1)$ \\
\hline 10 & Concerned about hearing emotionally difficult stories $(n=371)$ & $202(54.2)$ \\
\hline 11 & Discussing my health condition on social media worries me due to privacy $(n=373)$ & $146(39.7)$ \\
\hline 12 & Desire to reconnect with healthy peers and not other cancer patients $(n=368)$ & $31(8.3)$ \\
\hline 13 & Using social media is difficult for me $(n=373)$ & $24(6.5)$ \\
\hline & Access to a computer or mobile device is difficult for me $(n=372)$ & $15(4.0)$ \\
\hline
\end{tabular}

\subsection{Interest and Preferences for Digital Peer Navigation}

Half of the sample $(n=186,48.9 \%)$ indicated a desire to connect with a peer navigator who is a cancer survivor and who has received training to help others through the cancer experience (Table 4). Two-thirds indicated a desire to be a peer navigator $(n=231,62.9 \%)$ and willingness to attend a peer navigator training program $(n=231,63.1 \%)$.

Table 4. Interest and preferences for digital peer navigation.

\begin{tabular}{|c|c|c|}
\hline Variable $(n)$ & Category & Count $(\%)$ \\
\hline Interest in being connected with a peer navigator $(n=380)$ & Yes & $186(48.9)$ \\
\hline \multicolumn{3}{|l|}{ If no: $(n=195)$} \\
\hline & I do not think I need support & $82(42.1)$ \\
\hline & $\begin{array}{l}\text { I do not like to talk about my } \\
\text { problems }\end{array}$ & $21(10.8)$ \\
\hline & I believe I have adequate support & $88(45.1)$ \\
\hline & Other & $27(13.8)$ \\
\hline Interest in being a peer navigator $(n=367)$ & Yes & $231(62.9)$ \\
\hline \multirow[t]{3}{*}{ Importance of training for the peer navigator role? $(n=379)$} & Yes (slight to very important) & $257(67.8)$ \\
\hline & No & $86(22.7)$ \\
\hline & Unsure & $36(9.5)$ \\
\hline Willingness to attend an online peer navigator training program $(n=366)$ & Yes & $231(63.1)$ \\
\hline Interest in using a digital app to connect with a peer navigator $(n=378)$ & Yes & $310(82.0)$ \\
\hline \multirow[t]{2}{*}{ Digital app communication methods $(n=358)$} & One-on-one & $259(72.3)$ \\
\hline & In a group & $242(67.6)$ \\
\hline Types of support desired from a peer navigator? $(n=436)$ & Emotional support & $329(90.1)$ \\
\hline
\end{tabular}


Table 4. Cont.

\begin{tabular}{|c|c|c|}
\hline Variable $(n)$ & Category & Count $(\%)$ \\
\hline & Information support & $326(89.1)$ \\
\hline & Social companionship & $284(78.0)$ \\
\hline & Practical support & $269(73.6)$ \\
\hline \multirow[t]{5}{*}{ Best time to connect with a peer navigator $(n=368)$} & During diagnosis & $250(67.9)$ \\
\hline & Before treatment & $248(67.4)$ \\
\hline & During treatment & $295(80.2)$ \\
\hline & After treatment & $256(69.6)$ \\
\hline & If cancer recurs or spreads & $253(68.8)$ \\
\hline
\end{tabular}

Among those who did not desire a peer navigator, $42.1 \%(n=195)$ felt they did not need support and $45.1 \%(n=88)$ believed they had adequate support. A smaller proportion $(n=21,10.8 \%)$ indicated that they did not like to talk about their problems.

The majority of participants $(n=310,82 \%)$ indicated a desire to connect with a peer navigator if they could through a digital app, where they could view the profiles of AYA that match their criteria and select an AYA to talk with.

Participants indicated a greater need for emotional $(n=329,90.1 \%)$ and informational support $(n=326,89.1 \%)$ from a peer navigator than companionship $(n=284,78.0 \%)$ or practical support $(n=269,73.6 \%)$.

\subsection{Peer Matching Characteristics}

Ten matching characteristics were endorsed as important by over $50 \%$ of the sample (Table 5). The most important matching characteristics, endorsed by over $70 \%$ of the sample, were type of cancer $(n=329,88.4 \%)$, specific concerns $(n=317,86.1 \%)$, age-atdiagnosis $(n=316,86.1 \%)$, treatments received or considering $(n=314,85.1)$, current age $(n=302,82.1 \%)$, stage-of-disease $(n=278,75.7 \%)$, and coping style $(n=268,73.0 \%)$. The least important matching characteristics were sexual orientation $(n=63,17.2 \%)$ and race/ethnicity $(n=29,7.9 \%)$.

Table 5. Peer matching characteristics.

\begin{tabular}{lll}
\hline Rank & Matching Characteristics $(n)^{*}$ & Count (\%) \\
\hline 1 & Type of cancer $(n=372)$ & $329(88.4)$ \\
\hline 2 & Specific concerns $($ e.g., side effects, return to work) $(n=368)$ & $317(86.1)$ \\
\hline 3 & Age at diagnosis $(n=367)$ & $316(86.1)$ \\
\hline 4 & Treatments received/considering $(n=369)$ & $314(85.1)$ \\
\hline 5 & Current age $(n=368)$ & $302(82.1)$ \\
\hline 6 & Stage of disease $(n=367)$ & $278(75.7)$ \\
\hline 7 & Coping style $(n=367)$ & $268(73.0)$ \\
\hline 9 & Personality style $(n=368)$ & $237(64.4)$ \\
\hline 10 & Geographic region where you live $(n=365)$ & $229(62.7)$ \\
\hline 11 & Hobbies/interests $(n=364)$ & $191(52.5)$ \\
\hline 12 & Gender $(n=367)$ & $167(45.5)$ \\
\hline 13 & Hospital where you were treated $(n=368)$ & $144(39.1)$ \\
\hline 14 & Religion/spirituality $(n=357)$ & $132(37.0)$ \\
\hline
\end{tabular}


Table 5. Cont.

\begin{tabular}{llc}
\hline Rank & Matching Characteristics $(n) *$ & Count (\%) \\
\hline 15 & Education $(n=368)$ & $115(31.3)$ \\
\hline 16 & Sexual orientation $(n=367)$ & $63(17.2)$ \\
\hline 17 & Race/ethnicity $(n=368)$ & $29(7.9)$ \\
\hline
\end{tabular}

* Participants were asked to rate the extent to which these variables were important matching characteristics on a 4 -point Likert scale $(1=$ not at all important, 2 = not sure, $3=$ somewhat important, $4=$ very important $)$. Responses were dichotomized as not important vs. not sure, somewhat important, very important.

\section{Discussion}

It is evident from our study that the majority of AYA with cancer desire peer support from other AYA, as well as specialized support from a peer navigator. The results of this study will inform the development of an AYA-specific digital peer navigation program, which, to date, has not been explored. Although the majority of participants indicated a desire for peer support, AYA rarely asked their healthcare teams about peer support, and rather relied on their healthcare professionals to raise the topic. A similar reluctance to seek support for physical and psychosocial concerns was noted in a national population-based study of AYA [9], with participants citing not wanting to ask for help, being told that it was normal to feel the way they did or embarrassment as reasons for not seeking help [9]. Other research has found that AYA are often uncomfortable discussing non-medical issues with healthcare professionals [15], highlighting the importance of training healthcare professionals to be proactive in raising salient issues and referring AYA to available support resources [14].

Despite the widespread desire for peer support, many were still not able to access it. AYA rated the inconvenience of in-person support groups, the difficulty of finding AYA with whom they could relate, and the lack of AYA-specific support programs as the most important access barriers. AYA require and prefer AYA-specific support programs due to their distinct needs related to their age and life stage [12-14] and have advocated for online delivery methods $[13,16]$. Research has shown that AYA experience challenges in forming new social relationships with non-cancer peers due to their developmental stage and because peers without cancer cannot relate to the problems that accompany a cancer diagnosis [11,14]. However, there remains a paucity of research investigating the specific interpersonal concerns that may discourage AYA from seeking support from cancer peers. Our study has revealed that a significant proportion of AYA (e.g., 50 to $60 \%$ ) have concerns about being around negative-minded cancer patients, getting close to someone who may die, and hearing emotionally difficult stories. These relevant and important concerns reflect an aversion to engaging in emotion-focused coping and making social comparisons with others who are worse off, both of which can increase distress and lower self-esteem [35,36].

This study has confirmed that AYA are overwhelmingly interested in using a digital app to access peer support. In fact, the desire to connect with a peer navigator doubled if participants had the option through a digital app, where they could browse and select from the profiles of AYA peer navigators that match their criteria. This functionality aligns with the popular profile-based social networking software with which AYA are familiar [16], and offers AYA a degree of choice and control over their interactions with others, which is important in other cancer populations [20]. Research by Panier found that AYA have the desire to use technology to access a navigator, but would prefer to meet in-person for the first interaction [15]. Uniquely, our study, which was conducted before the COVID-19 pandemic, provides evidence in favor of peer support programs for AYA that are exclusively technology-based. This is a particularly important finding given the transition to virtual care necessitated by the COVID-19 pandemic, and will help inform the design and implementation of virtual support programs beyond the pandemic. This study has also re-confirmed [37] that AYA have the desire to give back and help others through the cancer experience. In our cohort, the majority of AYA were interested in volunteering 
to be a peer navigator, agreed that training for the role would be important, and would be willing to attend an online peer navigation training program. These findings hold promise for the success of a future peer navigation program for AYA, given that training in core competencies is critical for effectiveness and sustainability [38,39].

According to optimal matching theory, the effects of social support will be greatest if matched to the demands of the stressor and the needs of the support seeker [40]. In other words, if emotional support is needed, informational support will be unhelpful. This study indicates a greater need for both emotional (e.g., expression of feelings/concerns, and displays of empathy, caring, and reassurance) and informational support (e.g., resources or advice regarding a problem) from a peer and a peer navigator, rather than companionship (e.g., hanging out and performing normal social things) or practical support (e.g., daily chores, child care, getting to appointments, and help with finances). Other research has found that AYA desire emotional encouragement and information resources from a navigator [15]. In our sample, the desire for companionship and practical support was fairly high, nuanced by the preference for more companionship from a peer, and more practical support from a peer navigator. These findings align with the different types of support typically provided by a peer versus a peer navigator, and demonstrate a need for both. The high proportion of AYA desiring companionship and practical support is expected, given that cancer can disrupt existing relationships with non-cancer peers $(11,14)$ and cause a renewed dependence on parents for practical support and financial assistance [7]. Moreover, practical support could vary based on age, with younger AYA needing assistance with school and basic information regarding health insurance, while older AYA may have concerns regarding their family's needs and finances [15]. Support from a peer navigator could address these practical concerns, and lower the burden of care for parents and families [18].

To our knowledge, this is the first study to have investigated the characteristics that AYA are looking for in a peer navigator. AYA clearly desire to be matched with a peer navigator diagnosed with a similar type of cancer, at a similar age, and who has experienced similar concerns or treatment side effects. Other important matching characteristics included coping style, personality, geographic region, and hobbies. Matching based on sociodemographic factors was least important. The lower importance rankings of education, gender, sexual orientation, and race/ethnicity as matching criteria may be due to the insufficient diversity in the sample, given that most of the participants were college/university educated, and identified as cis-gender, heterosexual, and white or perhaps highlights the inclusivity of this younger demographic. For AYA, a digital app with a matching algorithm may partly address the challenges that AYA experience in finding other cancer patients with whom they can relate. Relatedness is a basic psychological need that is central to effective interpersonal relationships [41]. Further, research has found that patient satisfaction with navigators is largely based on the social and relational skills of the navigator and less on their technical skills [42]. Matching AYA with peer navigators who share similar characteristics could enhance their satisfaction with their navigator [42], and likely, the relevance of the information and support shared [40].

The study has certain limitations. Given its cross-sectional design, there may be some recall bias. While we aimed to obtain a representative sample of AYA both in-person and online to capture AYA across Canada, $80 \%$ of participants were from a single region (Ontario). Therefore, AYA living in other regions may have different views, given that AYA peer support programming varies across regions. The study sample is somewhat racially and ethnically diverse, but is not sufficiently diverse in terms of gender, sexual orientation, and rurality. In addition, the data on the rurality of the sample are limited as the response options (urban, suburban, town or rural) were not defined in terms of population density. Finally, there may be a level of selection bias, as those who are interested in peer support likely completed this survey. The degree of selection bias is likely higher among those recruited online versus those approached in clinics, as there was an effort made to approach every eligible patient during the study period. 


\section{Conclusions}

AYA desire support from other cancer peers, even though a significant proportion do not ultimately access peer support. A digital peer navigation program was desired by most and could overcome the barriers that AYA experience in accessing peer support. Future research should consider the specific matching characteristics and multidimensional support needs of AYA in the design of a digital peer navigation program for AYA.

Supplementary Materials: The following supporting information can be downloaded at: https: / / www.mdpi.com/article/10.3390/curroncol29020099/s1, Survey of Peer Support Needs and Preferences for Digital Peer Navigation among of Adolescents and Young Adults with Cancer.

Author Contributions: Conceptualization and methodology by J.L.B. with contributions from N.M.D., A.T., A.F.H., S.N.G., K.C., E.K.D., A.T., A.M., N.L.M. and A.A.G.; data collection and formal analysis, J.L.B., N.P. and S.S.; writing—original draft preparation, J.L.B.; writing-review and editing, J.L.B., N.P., S.S., N.M.D., A.T., A.F.H., S.N.G., K.C., E.K.D., A.M., N.L.M. and A.A.G.; supervision, J.L.B.; project administration, N.P.; funding acquisition, J.L.B. All authors have read and agreed to the published version of the manuscript.

Funding: This project was funded by the Canadian Centre for Applied Research in Cancer Control (ARCC). ARCC receives core funding from the Canadian Cancer Society Research Institute (grant no. 2105-703549).

Institutional Review Board Statement: The study was conducted in accordance with the Declaration of Helsinki, and approved by the Institutional Review Board of University Health Network (18-5386 and 3 August 2018).

Informed Consent Statement: Informed consent was obtained from all subjects involved in the study.

Acknowledgments: We would like to acknowledge the contributions of patient partners Priscilla Estrada and Sarah Johnson. This paper is dedicated to the memory of Sarah Johnson, whose wisdom and insight advanced our understanding of the needs and experiences of adolescents and young adults with cancer and will contribute to improving their care and quality of life.

Conflicts of Interest: The authors declare no conflict of interest.

\section{References}

1. Canadian Partnership Against Cancer. Adolescents and Young Adults with Cancer I Cancer System Performance; Canadian Partnership Against Cancer: Toronto, ON, Canada, 2017. Available online: https:/ /www.systemperformance.ca/report/adolescents-youngadults-cancer/ (accessed on 5 January 2022).

2. Lang, M.J.; Giese-Davis, J.; Patton, S.B.; Campbell, D.J. Does age matter? Comparing post-treatment psychosocial outcomes in young adult and older adult cancer survivors with their cancer-free peers. Psychooncology 2017, 27, 1404-1411. [CrossRef]

3. Woodward, E.; Jessop, M.; Glaser, A.; Stark, D. Late effects in survivors of teenage and young adult cancer: Does age matter? Ann. Oncol. 2011, 22, 2561-2568. [CrossRef]

4. Lane, B.; Fowler, K.; Eaton, G.; Chalifour, K.; Garland, S.N. Prevalence and factors associated with high levels of distress in young adult cancer survivors compared to matched peers. Support. Care Cancer 2020, 29, 2653-2662. [CrossRef]

5. Mahon, K.N.; Garland, S.N.; Eaton, G.; Chalifour, K.; Lane, B.E.; Fowler, K.; Gambin, L.; Clair, L. The financial impact of cancer on Canadian young adults. J. Cancer Surviv. 2021,1-13. [CrossRef]

6. Salsman, J.M.; Bingen, K.; Barr, R.D.; Freyer, D.R. Understanding, measuring, and addressing the financial impact of cancer on adolescents and young adults. Pediatr. Blood Cancer 2019, 66, e27660. [CrossRef]

7. Zebrack, B.; Isaacson, S. Psychosocial Care of Adolescent and Young Adult Patients with Cancer and Survivors. J. Clin. Oncol. 2012, 30, 1221-1226. [CrossRef]

8. Pt, M.L.M.; Med, J.K.P.; Jones, J.M.; Amin, L.; Chang, E.; Korenblum, C.; Mina, D.S.; McCabe, L.; Mitchell, L.; Giuliani, M. Reimagining care for adolescent and young adult cancer programs: Moving with the times. Cancer 2016, 122, 1038-1046. [CrossRef]

9. Jones, J.M.; Fitch, M.; Bongard, J.; Maganti, M.; Gupta, A.; D’Agostino, N.; Korenblum, C. The Needs and Experiences of Post-Treatment Adolescent and Young Adult Cancer Survivors. J. Clin. Med. 2020, 9, 1444. [CrossRef]

10. Keegan, T.H.M.; AYA HOPE Study Collaborative Group; Lichtensztajn, D.; Kato, I.; Kent, E.E.; Wu, X.-C.; West, M.M.; Hamilton, A.S.; Zebrack, B.; Bellizzi, K.M.; et al. Unmet adolescent and young adult cancer survivors information and service needs: A population-based cancer registry study. J. Cancer Surviv. 2012, 6, 239-250. [CrossRef] 
11. Kent, E.E.; Smith, A.W.; Keegan, T.H.M.; Lynch, C.F.; Wu, X.-C.; Hamilton, A.S.; Kato, I.; Schwartz, S. Talking About Cancer and Meeting Peer Survivors: Social Information Needs of Adolescents and Young Adults Diagnosed with Cancer. J. Adolesc. Young Adult Oncol. 2013, 2, 44-52. [CrossRef]

12. Gupta, A.A.; Edelstein, K.; Albert-Green, A.; D'Agostino, N. Assessing information and service needs of young adults with cancer at a single institution: The importance of information on cancer diagnosis, fertility preservation, diet, and exercise. Support. Care Cancer 2013, 21, 2477-2484. [CrossRef] [PubMed]

13. Cheung, C.K.; Zebrack, B. What do adolescents and young adults want from cancer resources? Insights from a Delphi panel of AYA patients. Support. Care Cancer 2016, 25, 119-126. [CrossRef] [PubMed]

14. D'Agostino, N.M.; Edelstein, K. Psychosocial Challenges and Resource Needs of Young Adult Cancer Survivors: Implications for Program Development. J. Psychosoc. Oncol. 2013, 31, 585-600. [CrossRef] [PubMed]

15. Pannier, S.T.; Warner, E.L.; Fowler, B.; Fair, D.; Salmon, S.K.; Kirchhoff, A.C. Age-Specific Patient Navigation Preferences Among Adolescents and Young Adults with Cancer. J. Cancer Educ. 2017, 34, 242-251. [CrossRef]

16. Aggarwal, R.; Hueniken, K.; Eng, L.; Kassirian, S.; Geist, I.; Balaratnam, K.; Liang, M.; Paulo, C.B.; Geist, A.; Rao, P.; et al. Health-related social media use and preferences of adolescent and young adult cancer patients for virtual programming. Support. Care Cancer 2020, 28, 4789-4801. [CrossRef]

17. Bender, J. Chapter 3: Cancer Virtual Communities in the Era of Personalized Medicine: Perspectives on Scope, Use and Impact. In Novel Applications of Virtual Communities in Healthcare Settings; El Morr, C., Ed.; IGI Global: Hershey, PA, USA, 2018 ; pp. 56-92.

18. Ussher, J.; Kirsten, L.; Butow, P.; Sandoval, M. What do cancer support groups provide which other supportive relationships do not? The experience of peer support groups for people with cancer. Soc. Sci. Med. 2006, 62, 2565-2576. [CrossRef]

19. Hoey, L.M.; Ieropoli, S.C.; White, V.M.; Jefford, M. Systematic review of peer-support programs for people with cancer. Patient Educ. Couns. 2008, 70, 315-337. [CrossRef]

20. Bender, J.L.; Katz, J.; Ferris, L.E.; Jadad, A.R. What is the role of online support from the perspective of facilitators of face-to-face support groups? A multi-method study of the use of breast cancer online communities. Patient Educ. Couns. 2013, 93, 472-479. [CrossRef]

21. Wells, K.J.; Battaglia, T.A.; Dudley, D.J.; Garcia, R.; Greene, A.; Calhoun, E. Patient navigation: State of the art or is it science? Cancer 2008, 113, 1999-2010. [CrossRef]

22. Paskett, E.D.; Harrop, J.P.; Wells, K.J. Patient navigation: An update on the state of the science. CA A Cancer J. Clin. 2011, 61, 237-249. [CrossRef]

23. Ali-Faisal, S.F.; Colella, T.J.; Medina-Jaudes, N.; Scott, L.B. The effectiveness of patient navigation to improve healthcare utilization outcomes: A meta-analysis of randomized controlled trials. Patient Educ. Couns. 2017, 100, 436-448. [CrossRef]

24. Baik, S.H.; Gallo, L.C.; Wells, K.J. Patient Navigation in Breast Cancer Treatment and Survivorship: A Systematic Review. J. Clin. Oncol. 2016, 34, 3686-3696. [CrossRef] [PubMed]

25. Freund, K.M.; Battaglia, T.A.; ACalhoun, E.; Darnell, J.S.; Dudley, D.J.; Fiscella, K.; Hare, M.L.; Laverda, N.L.; Lee, J.-H.; Levine, P.H.; et al. Impact of Patient Navigation on Timely Cancer Care: The Patient Navigation Research Program. JNCI J. Natl. Cancer Inst. 2014, 106, dju115. [CrossRef] [PubMed]

26. BernardoMph, B.M.B.; Zhang, X.; Ms, C.M.B.; Meadows, R.; Paskett, E.D. The efficacy and cost-effectiveness of patient navigation programs across the cancer continuum: A systematic review. Cancer 2019, 125, 2747-2761. [CrossRef]

27. Canadian Parntership Against Cancer. Navigation: A Guide to Implementing Best Practices in Person-Centred Care; Canadian Partnership Against Cancer: Toronto, ON, Canada, 2012.

28. Statistics Canada. Life in the Fast Lane: How are Canadians Managing? Statistics Canada: Ottawa, ON, Canada, 2017. Available online: https:/ / www150.statcan.gc.ca/n1/daily-quotidien/171114/dq171114a-eng.htm?HPA=1 (accessed on 5 January 2022).

29. Casillas, J.N.; Schwartz, L.F.; Crespi, C.M.; Ganz, P.A.; Kahn, K.L.; Stuber, M.L.; Bastani, R.; Alquaddomi, F.; Estrin, D.L. The use of mobile technology and peer navigation to promote adolescent and young adult (AYA) cancer survivorship care: Results of a randomized controlled trial. J. Cancer Surviv. 2019, 13, 580-592. [CrossRef]

30. Canadian Institutes of Health Research. Strategy for Patient-Oriented Research (SPOR)_Patient Engagement Framezork; Canadian Institutes of Health Research: Ottawa, ON, Canada, 2014.

31. Domecq, J.P.; Prutsky, G.; Elraiyah, T.; Wang, Z.; Nabhan, M.; Shippee, N.; Brito, J.P.; Boehmer, K.; Hasan, R.; Firwana, B.; et al. Patient engagement in research: A systematic review. BMC Health Serv. Res. 2014, 14, 89. [CrossRef]

32. Forsythe, M.L.P.; Ellis, L.E.; Ba, L.E.; Sabharwal, R.; Rein, A.; Konopka, K.; Frank, L. Patient and Stakeholder Engagement in the PCORI Pilot Projects: Description and Lessons Learned. J. Gen. Intern. Med. 2015, 31, 13-21. [CrossRef]

33. Von Elm, E.; Altman, D.G.; Egger, M.; Pocock, S.J.; Gøtzsche, P.C.; Vandenbroucke, J.P. The Strengthening the Reporting of Observational Studies in Epidemiology (STROBE) Statement: Guidelines for Reporting Observational Studies. PLoS Med. 2007, 4, e296. [CrossRef]

34. Bender, J.L.; Cyr, A.B.; Arbuckle, L.; Ferris, L. Ethics and Privacy Implications of Using the Internet and social media to Recruit Participants for Health Research: A Privacy-by-Design Framework for Online Recruitment. J. Med. Internet Res. 2017, 19, e104. [CrossRef]

35. Lazarus, S.; Folkman, R. Stress, Appraisl and Coping; Springer: New York, NY, USA, 1984.

36. Festinger, L. A Theory of Social Comparison Processes. Hum. Relat. 1954, 7, 117-140. [CrossRef]

37. Wazneh, L.; Tsimicalis, A.; Loiselle, C. An Exploration of Young Adults' Perceptions of "Venturing Out Beyond Our Cancer" (VOBOC) as Tangible Cancer Support Services. Oncol. Nurs. Forum 2016, 43, E34-E42. [CrossRef] [PubMed] 
38. Ustjanauskas, A.E.; Bredice, M.; Nuhaily, S.; Kath, L.; Wells, K.J. Training in Patient Navigation. Heal. Promot. Pr. 2015, 17, 373-381. [CrossRef] [PubMed]

39. Cutrona, C.; Russel, D. Type of social support and specific stress: Toward a theory of optimal matching. In Social Support: An Interactional View; Sarason, B., Sarason, I., Piercem, G., Eds.; Wiley \& Sons: Oxford, UK, 1990; pp. 319-366.

40. Flora, P.; Bender, J.; Miller, A.; Parvin, L.; Soheilipour, S.; Maharaj, N.; Milosevic, E.; Matthew, A.; Kazanjian, A. Development of a Peer Navigator Core Competency Framework for Prostate Cancer. Support. Care Cancer 2020, 28, 2605-2614. [CrossRef]

41. Ryan, R.; Deci, E. Self-Determination Theory: Basic Psychological Needs in Motivation, Development, and Wellness; Guilford Press: New York, NY, USA, 2017.

42. Jean-Pierre, P.; Fiscella, K.; Winters, P.C.; Post, U.; Wells, K.J.; McKoy, J.M.; Battaglia, T.; Simon, M.A.; Kilbourn, K. Patient Navigation Research Program Group Psychometric development and reliability analysis of a patient satisfaction with interpersonal relationship with navigator measure: A multi-site patient navigation research program study. Psychooncology 2011, 21, 986-992. [CrossRef] [PubMed] 